Draneh of the Provincial Medical and Burgical Aseociation, at the meeting held on the 3nd of May. It was accompanied bJ a series of observations, in reference specially to tho operation of excision of the knee; but as those observations vere arranged mainly with the view of placing before $m y$ audience the present state of our experience on the question, in order to elicit discussion, and as 1 am preparing memoir upon the subject of the operation in all its bearings, I have contented myself, on the present occasion, with simply placing on record the case, together with a few comments on its more prominent features.

Assuredly, one of the most remarkable circumstances connected with the operation, is the entire absence of shock. There were never present any symptoms of such a condition. I believe most fully that the constitutional disturbance was diminished by the extirpation of the diseased parts; as the hectic and diarrhcea, markedly present before the operation, ceased on its performance. With regard to hømorrhage, the articular vessels, on being divided, spurted out for a moment, but did not require ligature. No venous oozing occurred. I was particularly struck by the continuance of the warmth in the limb, the temperature of which nerer varied. A slight amount of pain was experienced; much less, indeed, than what we should expect to find present in so large a wound, involving, as it did, the extremities of bones, rendered free to move on raw and tender surfaces. Yet, there was no starting of these extremities; there was no painful throbbing and quivering in their vicinity. The movements of the toes, and the command generally of the foot and leg, appeared to be scarcely interfered with. Within a few weeks, the patient could move the foot inwards or outwards with ease, or maintain it in the upright position. The suppuration was never profuse never so great as that which would arise from a flap amputation of a thigh of the same dimensions as the patient's. The granulations of the wound wanted tone, it is true; but that would be an inevitable condition of a large wound, involving thickened integument, and existing in a strumous habit.

The mode of operation which I adopted appears to me to be deserving of attention.

Having divided the soft parts by the semilunar incision, as first adopted by the late Mr. R. Mackenzie, ${ }^{*}$ and having turned back the Hlap containing the patella, so as fairly to expose the interior of the joint, I applied the saw to the femur and tibia, and divided the required amount from their ends by a careful use of the instrument; the soft parts being undisturbed by the needless introduction of a spatula. The separated extremity of the femur was then raised, and, together with the tibia, was removed by a dissection from above downwards; such ligamentous attachments as were left undestroyed by the ravages of the disease still being permitted to connect the two bones. By adopting this method, the time occupied in the operation was considerably shortened; but what was still more important, by thus keeping the connexion of the articular a tremities unbroken, their dissection from the popliteal 6. 3els was rendered afer and easier. By this process, the 2. . can hare the upper soft parts depressed by an is where the contiguity of the vessels is of comparat1 i ciripristance, whilst he is enabled himself to raise the back part vi the juint from the more perilous vicinity of the vessels inferioriy, sr as to complete the undertaking in safety.

Mülder, in the Hompital of Gröningen, first insisted upon this; though I an nc awart that his raluable suggestion has been carried out by iny une sitic my welf

Wachter, in his Dissevtutio thirryice de Articulis Extirpandis, observes:- "The :lustri"ts Milder did not deem it necessary to remore the a. " the bolic- separately, as Park did. Hence wo incoricevince arose; and the ends of the bones were able to be extir piatiol aduirably. These being taken away, nowhere, not in the deepest part of the wound, was the popliteal arterv uncurerits conse-

\footnotetext{
- This mechod was arret recommended by Mr. 8keg. (Jp. 8mo., p. 205.)
}

quently, there was little fear during the operntion loat if should be rounded."

In the preceding description of the plan I adopted, I that the soft parts were undisturbed by the needless intiro duction of a spatula. Now, so far as I am aware, this is the first instance in which the articular extremities have been so divided. Hitherto, a broad spatula has been introduced; and upon its protecting surface the bones hare been sawn through. The advantage derived from the operation I recommend-namely, that of avoiding disturbance of the soft tissues-1s so obvious, that I am surprised it has escaped observation.

Mr. Butcher, in his recent essayt on excision of the knee, minutely describes a particular saw, with which ho removes separately the protruded bones, cutting them from behind forwards, away from the vessels. Not, however, admitting the danger of sawing down to the soft parts, I cannot, in my own judgment, admit the advantage of this instrument in the operation in question, as described by this able surgeon.

Birmingham, May 1855.

\section{ON ONE OF THE CURABLE FORMS OF DEAFNESS.}

By THOMAS WESTROPP, Esq.

ROBERT LAMBERT, a porter waiting on steamers, came to the King Street Ear and Eye Dispensary for the first time on the 5th of December. He complained of deafness, which he said was a great inconvenience to him in the discharge of his business. (I could not help reflecting that there was no small amount of noise at the sailing and arrival of steam packets.) He could only hear a watch on touching. He was in good general health. On examining his ears with a speculum, I found the membrana tympani slightly thickened on both sides, and presenting an appearance $I$ had never before seen so well marked, and one which is not accurately described by authors; namely, a number of whitish strim running in various directions across the membrane, sometimes intercrossing each other irregularly. In the intervals between the fibrous cords, the drum presented almost its natural colour. Having gently syringed the ear, I ordered him to take a pill of colocynth and blue pill on two successive nights, that the bowels might be gently acted on, and to have a leech applied with proper precautions to the margin of each meatus.

In applying leeches to the ears, the following rules should be observed. The meatus should be filled with cotton wool, to prevent either the leech from biting too far in, which might cause severe pain, or the blood from trickling inwards, where it would clot and harden on the membrana tympani. A leech-glass is generally necessary; but I find that if a drop of blood is present on the part to which we want to apply the leech, there is not much trouble in getting it to adhere. This may be obtained by scratching the part with a pin. We should always previously wash away any cerumen or discharge, if present. The leech should not be allowed to bite far out on the surface of the auricle, because erysipelas is known to be produced at times by it. In young children, the bleeding should be stopped before the little patient is sent away, because hæmorrhage is sometimes very profuse from leech bites, more especially on or near the ear.

Dec. 7th. There was no improvement in hearing with the watch. He had neglected to apply the leeches. He was ordered to take a tablespoonful twice a day of the following mixture.

B Hydrargyri bichloridi gr. iss, Spiritús vini łss, Infusi cinchonæ $\zeta$ viiss. $M$.

- Osgium fines separatim auferre, necessarium non dusit cl. Prmecter. uti fecerit exc. Park. Nullum inde oriebetur incommodum, et optime these ossium exstirpari poterant. Hisce sublatis nusguam in parto rulnerts pro-

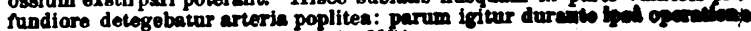
metas adorat, uo lilla lederetur." (p. ilf.)

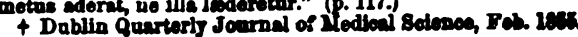


Deco gth. He had had the leechee applied, but out too in the surface of each auricle; in fact, where the conche meots the fose innominata. This was by no means chatisfactory as if they were properly applied, which drugas stisfactory as if they were properiy applied, a littlo of a gesk solution of nitrate of silver to each membrane, through weak solution of nitrate cotton, on the end of a probe, and a speculum, blister, properly adapted for the situation, to be applied behind the right ear at bed time.

Dec. 12th. The hearing was as at the last report. The blister did not rise: ho was ordered to apply another instead. Having syringed the ears, I applied some glycerine within each meatus, and ordered him to take a tablespoonful of the following mixture, and to omit the other.

Bo Hydrargyri biniodidi gr. ij,

Potassii iodidi jss,

Tinct. arnicæ montanæ $f_{\text {. }} \mathbf{j}^{\mathrm{iij}}$,

Infusi cinchonæ $₹$ viij. M.

Eachidose contained the eighth of a grain of biniodide of mercury.

Dec. 16th. He heard better with the right ear than with the left: the reverse was the case when he first applied for relief. There was no ptyalism as yet. He was ordered to continue the mixture. I dropped a watery solution of contrychnine into both ears, and applied half a grain of strychnine to the blistered surface. He was ordered to apply a blister behind the left ear.

Dec. 19th. The hcaring distance, as measured with a watch, was much about the same; but he said he remarked that he could hear the ticking and striking of his own clock more distinctly, and could hear conversation, when doing his business, much better. Ptyalism was just commencing. He was directed to continue the mixture as before. I brushed each membrana tympani with a twenty-grain solution of nitrate of silver; and directed him when smoking to endeavour to force the tobacco smoke into each ear, by holding the nose with his fingers, shutting the lips, and then (his mouth being full of smoke) making a forcible attempt to blow through his nose.

This man did not come any more, though I recommended him to attend for a few weeks longer. I suppose that having much business to attend to, and feeling well in every other respect, and hearing almost sufficiently well for his wants, he did not think it worth while to take any more trouble. I believe his case to have been capable of much further improvement, had he attended regularly; as the thickening of parts, consequent on slight inflammation of only a few months' date, was not extreme, nor complicated with other affections. I was rather surprised at his attending to the condition of his ears so soon, as people in his rank of life do not usually apply till two or three years have elapsed, and till they have found out by personal experience that the usual nostrums have done them no good, and the idea that "it's only a cold" has ceased to be consolatory; when the satisfactory discharge of their duties is impaired, then they begin to think it worth while to see whether a regular practitioner can do them any good, which unfortunately is seldom the case, as they have previously bought screral of the speedy cures and books advertised in the newspapers, both by professed quacks and unprincipled practitioners.

Bristol, Maj 1855.

\section{PERISCOPIC REVIEW.}

\section{PRACIICE OF IEDTCITE AND PATHOLOGY.} GLEANINGS FROM THE JOURLALS.

STEARRHCES NIGRICANS, OR BLACK DISCOLORAT UN OF THE SKIN OP THE FACE.

In the Dublin Quarterly Journal of Medical: 'cience for May 1855 , Dr. J. M. Neligan has published an eq' ay on black discoloration of the skin of the face. The affectic, 1 (at least in the intense form described by Dr. Neligan) is rare, but some examples hare been well described, especially by the late Mr. Teevan, in vol. Ixviii of the Med.-Chir. Transactions, ana Dr. Yonge of Plymouth, in the Philosophical Transactions, in the year 1709. The history of the case related by Dr. Neligan was commu-
nicated to him by Dr. Quinan, physician to the Donnybrook Dispensary. The following is an abstract.

Consary. The fllown unmaried a dressmaker, of leucophlegmCASE. E. D., afed atic habit, had been in good health till about the age of litogether. the calamenia, which hach of erysipelatous redness apphortly afterwarts, a largo patch of peared on the right side of the bods, andion being prolonged and it reappeared and disappeared (its duration being prolonged each time) at each monthly period. Tartar emetic in small doses was prescribed by a medical man, under the idea that the redness was from erysipelas. She, however, had a fearful attack of nausea and romiting, and had since been subject to sickness of the stomach, occurring regularly half an hour after sickness of the stomach, occurn, followed by vomiting of food. She had a troublesome cough; with loss of appetite and of She had a troublesome cough; with loss of appetite and of strength. In August last, she went to England to try the efrect of a short sea voyage and change of air; but she was there told by a medical gentleman that she was threatened with consumpby a medical gentleman that she At this time the erysipelatous tion, and she returned home. At this time the erysipelatous redness ceased to appear, though the catamenia were still rednent; and she perceived, after a fit of retching, some blood in lier expectoration. At the next monthly return (September) in her expectoration. At the next monthly return (September) the symptoms were more violent; and she threw up about half
a pint of reddish-brown matter every morning for four or five days. In October the vomiting returned : and now, for the first days. In October the vom stain appeared at the inner canthus of time, a dark bluish.black stain appeared at the inner canthus of the left eye. When Dr. Quinan saw her there was a large patch under esch eye; the skin was tender; and the romiting continued every morning. The treatment employed consisted in the administration of nourishing diet, tonics, emmenagogues, and stimulants, with the free use of open air exercise. Dr. Neligan saw the patient in December 1854. The girl was much emaciated, except in the face, and highly hysterical. The dark stains now covered nearly the whole of the right upper eyelid, and part of the left; both under cyelids were completely stained, and the dark patch extended on the right cheek. The colour was precisely that which would be produced by Indian ink, and rather set off, or even gave additional beauty to a pleasing face. On cramining with a lens, it was evident that the stain was dotted over the skin, corresponding to the sebaceous glands. No attempt was made to remove the stain by washing, on account of the pain which she had found the process to induce, and because the surface of the skin was exquisitely tender. In April 1855, Dr. Neligan again saw the patient. The general health was moln ough and vomiting of dark matter had diminished. The dark stains had become deeper in colour and had extended below the malar bones and on the alm of the nose. On the skin at the confines of the stains an exudation of the yellow matter of the sebaceous glands had taken place, precisely similar to what occurs in stearrhoea flavescens; and wherever this sebaceous tluid had been rubbed off, or the subjacent parts irritated, the integuments were inflamed, the sebaceous follicles hypertrophied, and their orifices enlargech, and in some cases filled with black matter.

Dr. Neligan also relates the history of a case communicated to him by Professnr Law, of the College of Physicians in Ireland, occurring in a lady who consulted him twelve [three?] years ccur 'I'his case agreed with that of Dr. Quinan in the irritability of stomach, perverted appetite, and uterine derangement; but in Irofessor Law's case there was no pain, though there was some aversion to light.

All the cases of black discoloration of the face which have been recorded, 1)r. Neligan states, occurred in young females affected with derangement or partial or total suppression of the catamenia: in three-those most accurately reported-there was black romiting; and in one at least the black colour disappeared with the restoration of the uterine function. Dr. Neligan terms the disease stcarrhca nigricans; and considers that, as not uncommonly occurs in females in whom the menstrual function is deranged, the scbaceous secretion is augmented in quantity, and in some cases is stained with the colouring matter of the blood-this being analogous to black coloured romiting, dark sputa, dark urine, or hæmorrhagic subcutaneous extravasation. In the treatment, the evident indication is to restore a healthy state to the uterine function.

NGERENGERE, OR LEPRA GANGRENOSA OF THE NEW ZEALASDERB.

In an interesting article on the Customs and Diseases of the New Zealanders, published in the British and Foreign MedicoChirurgical Review for April and October 1854, Dr. A. S. THoxches deribes a cutaneons disease prevalent among that people. The disease commences with a cutaneous eruption on the 